\title{
1 Controls on turbulent mixing on the West Antarctic Peninsula shelf
}

2 J. Alexander Brearley ${ }^{1 *}$, Michael P. Meredith ${ }^{1}$, Alberto C. Naveira Garabato ${ }^{2}$, Hugh J. Venables ${ }^{1}$ 3 and Mark E. Inall ${ }^{3,4}$

$5 \quad{ }^{1}$ British Antarctic Survey, High Cross, Madingley Road, Cambridge, CB3 0ET, UK.

$6{ }^{2}$ University of Southampton, National Oceanography Centre Southampton, European Way, 7 Southampton, SO14 3ZH, UK.

$8 \quad{ }^{3}$ Scottish Association of Marine Sciences, Scottish Marine Institute, Oban, PA37 1QA, UK.

$9{ }^{4}$ University of Edinburgh, School of Geosciences Edinburgh EH9 3FE, UK.

$10 \quad$ Corresponding author jambre@bas.ac.uk

\section{Abstract}

The ocean-to-atmosphere heat budget of the West Antarctic Peninsula is controlled in part by the upward flux of heat from the warm Circumpolar Deep Water (CDW) layer that resides below $\sim 200 \mathrm{~m}$ to the Antarctic Surface Water (AASW), a water mass which varies strongly on a seasonal basis. Upwelling and mixing of CDW influence the formation of sea ice in the region and affect biological productivity and functioning of the ecosystem through their delivery of nutrients. In this study, 2.5-year time series of both Acoustic Doppler Current Profiler (ADCP) and conductivitytemperature-depth (CTD) data are used to quantify both the diapycnal diffusivity $\kappa$ and the vertical heat flux $Q$ at the interface between CDW and AASW. Over the period of the study, a mean upward heat flux of $\sim 1 \mathrm{~W} \mathrm{~m}^{-2}$ is estimated, with the largest heat fluxes occurring shortly after the loss of winter fast ice when the water column is first exposed to wind stress without being strongly stratified by salinity. Differences in mixing mechanisms between winter and summer seasons are investigated. Whilst tidally-driven mixing at the study site occurs year-round, but is likely to be relatively weak, a strong increase in counterclockwise-polarized near-inertial energy (and shear) is 
observed during the fast-ice-free season, suggesting that the direct impact of storms on the ocean surface is responsible for much of the observed mixing at the site. Given the rapid reduction in seaice duration in this region in the last 30 years, a shift towards an increasingly wind-dominated mixing regime may be taking place.

\section{Introduction}

The intrusion of warm, saline water masses onto polar ocean shelves is believed to be an important pathway for the delivery of heat to the base of glaciers and/or ice shelves [e.g. Straneo et al., 2012; Martinson and McKee, 2012; Inall et al., 2014]. In the Antarctic, relatively warm and unmodified Circumpolar Deep Water (CDW) floods onto the West Antarctic Peninsula (WAP) shelf below $200 \mathrm{~m}$, particularly in the vicinity of deep, glacially-scoured troughs such as the Marguerite Trough

(Fig. 1). Several studies point to eddy shedding, topographic steering and Ekman processes as being likely candidates for fluxing this water mass landward from the Antarctic Circumpolar Current (ACC) [Moffat et al., 2009; Klinck and Dinniman, 2010]. However, the heat budget of the shelf itself is not well constrained, with estimates of both lateral and vertical heat fluxes being poorly quantified. These fluxes strongly control the interaction between the CDW and the overlying Antarctic Surface Water (AASW), which in turn can affect the volume of seasonal sea ice formed and the heat ultimately delivered to the atmosphere [Valkonen et al., 2008] and cryosphere [Pritchard et al., 2012; Rignot et al., 2013].

The WAP and its surrounding ice shelves (Fig. 1a) are undergoing rapid changes in environmental conditions, driven by forcing that includes atmospheric warming [Turner et al., 2005] and increased wind stresses [Marshall, 2003; Stammerjohn et al., 2008a]. Stronger winds, believed to be associated with a positive phase of the Southern Annular Mode (SAM), have been linked to reduced thickness and longevity of sea-ice cover [Stammerjohn et al., 2008b]. In addition, rapid 
summertime warming of the upper $100 \mathrm{~m}$ of the water column has been observed [Meredith and King, 2005] and over $80 \%$ of the glaciers on the WAP shelf are retreating, with retreat rates increasing [Cook et al., 2005; Cook et al., 2014].

Recent evidence from both the Arctic and Antarctic suggest that these oceanographic and sea-ice changes have the potential to change significantly the diapycnal mixing of heat, salt and nutrients on polar ocean continental shelves. For instance, loss of sea ice in the Arctic has been linked to stronger mixing across the base of the pycnocline through the input of near-inertial shear [Rainville and Woodgate, 2009]. Hyatt et al. [2011] postulate that sea ice within Marguerite Bay on the WAP continental shelf acts as both a thermal and mechanical barrier during winter, reducing diapycnal mixing. In addition, a change in near-surface stratification associated with an increase in the length of the fast-ice-free season may also affect mean values of diapycnal diffusivity $\kappa$. This can occur either by a reduction in the value of $N^{2}$ in the Osborn equation (which translates turbulent kinetic energy dissipation, $\varepsilon$, into diffusivity $\kappa)$ [Osborn, 1980], or through the impact of changing stratification on internal tides, which have been identified as being important farther north on the South Scotia Ridge [Padman et al., 2006] and on the continental shelf itself [Wallace et al., 2008]. These changes in diapycnal mixing have the potential to feed back on the volume of sea ice produced (for example increased upward heat fluxes could reduce further the volume of sea ice, or reduced albedo could increase the summer heat content of the ocean). Such changes could lead to large shifts in both upper ocean heat and salt properties and in air-sea fluxes; however the complex web of feedbacks remains insufficiently understood.

This paper uses a time series of co-located moored current velocity and conductivity-temperaturedepth (CTD) measurements collected in Ryder Bay (Fig. 1b) between January 2005 and May 2007 to investigate variability in turbulent diffusivity and vertical heat fluxes over 2.5 years. Background information about the measurements is given in Clarke et al. [2008], Meredith et al. [2010] and 


\section{.}

Venables et al. [2013]. These were accompanied by in-situ meteorological and sea ice observations from the meteorological station at the British Antarctic Survey research station at Rothera, $3 \mathrm{~km}$ distant (Fig. 1b). The focus of the paper is on the time variability of both diapycnal mixing and the vertical heat fluxes between the CDW and AASW layers, and the relationship between these quantities and wind- and internal-tide processes that have been conjectured to drive vertical mixing on the WAP shelf. The role of double diffusive mixing is also considered.

\section{Data}

2.1. Acoustic Doppler Current Profiler (ADCP) and Conductivity-Temperature-Depth (CTD) Data

Horizontal velocities $u$ and $v$ were acquired every 15 minutes in 4 m vertical bins, from a moored 75khz Acoustic Doppler Current Profiler (ADCP) ensonifying the top $200 \mathrm{~m}$ of the water column at a position close to $67^{\circ} 34^{\prime} \mathrm{S}, 68^{\circ} 14^{\prime} \mathrm{W}$ for the period 25 January 2005 to 9 April 2007. This data set, known as the Rothera Time Series (RaTS) Site 1 (Fig. 1b), was fully described by Wallace et al. [2008]. The instrument was deployed for three separate periods in $520 \mathrm{~m}$ of water, these being 25 January 2005 to 15 February 2006 (hereafter known as deployment 1), 17 February 2006 to 16 December 2006 (deployment 2) and 17 December 2006 to 9 April 2007 (deployment 3).

8

Accompanying these velocity data, full-depth $(520 \mathrm{~m})$ CTD data were acquired at approximately two-week intervals throughout the year, these measurements being taken either from a small rigid inflatable boat or through a hole drilled in the fast ice. Full details are given in Venables and Meredith [2014]. After calibration, temperature $T$ is accurate to $0.002^{\circ} \mathrm{C}$ and salinity $S$ to 0.005 .

03

\subsection{Estimating turbulent dissipation $\varepsilon$ and diapycnal diffusivity $\kappa$}


In the absence of direct microstructure estimates, turbulent kinetic energy dissipation $\varepsilon$ was estimated using a finescale parameterization based on wave-wave interaction theory [Gregg et al, 2003]. The alternative technique of estimating $\varepsilon$ from Thorpe scales was considered, but the difficulty of estimating CTD package motion from the hand-winch CTD at Rothera rendered this

111 Estimates of buoyancy frequency squared $\left(N^{2}\right)$ were calculated from the $1 \mathrm{~m}$ CTD time series, and 112 then smoothed vertically using a 10-point median filter and interpolated onto the 15-minute time113 base of the ADCP data. Vertical shear was then evaluated at each timestep, and spectra then 114 produced of $\left\langle V_{z} / \bar{N}\right\rangle^{2}$ (hereafter known as buoyancy-normalized shear). This quantity was then 115 averaged over one day to reduce noise. There are strong limitations to the application of this scheme 116 to a coastal shelf environment. These include (amongst other factors) that coastal regions tend to be 117 close to wave generation sources; that the internal wave field may be non-stationary; that the field 118 itself does not bear close resemblance to a Garrett-Munk (GM) type spectrum [Garrett and Munk, 119 1975]; and that mixing may be driven by other processes (e.g. double diffusive convection, direct 120 convective processes). Thus, there are likely to be significant errors in the estimation of $\varepsilon$, possibly 121 by up to an order of magnitude [Waterman et al., 2013]. However, in the absence of direct estimates 122 of $\varepsilon$ from microstructure, we employed the technique primarily as a method of distinguishing 123 periods of elevated and suppressed mixing. To test one of the key limitations (that of assuming a 124 GM wavefield), we examined the individual shear spectra from the ADCP (Fig. 2a). These were 125 bluer than the canonical GM shape, but not grossly different to the spectra in many other literature 126 estimates that have applied the technique successfully (e.g. Kunze et al. [2006]). We also confined 127 our estimates of $N^{2}$ to the layer between 100 and $200 \mathrm{~m}$, in order to avoid the direct convective 128 processes that dominate the upper $100 \mathrm{~m}$ of the water column. A discussion of the likely impact of 129 double diffusive processes is given in Section 2.3. 
131 The daily buoyancy-normalized vertical shear spectra $\left\langle V_{z} / \bar{N}\right\rangle^{2}$ (which were corrected for range 132 averaging and finite differencing as in Polzin et al. [2002]) were integrated between wavelengths of $13380 \mathrm{~m}$ and $130 \mathrm{~m}$ (Fig. 2a,b) - note that the depth range 10-200 $\mathrm{m}$ was used for this calculation.

134 Dissipation rate $\varepsilon$ was then estimated from the ratio of the normalized shear to the integrated shear 135 from a theoretical Garrett-Munk spectrum (Fig. 2c), as follows:

$\varepsilon=\varepsilon_{0} \frac{f}{f_{0}} \frac{\cosh ^{-1}(N / f)}{\cosh ^{-1}\left(N_{0} / f_{0}\right)} \frac{\left\langle V_{z} / \bar{N}\right\rangle^{2}}{\left\langle V_{z_{G M}} / N_{0}\right\rangle^{2}} h_{1}\left(R_{\omega}\right)$

139 In this equation, $\varepsilon_{0}=7.8 \times 10^{-10} \mathrm{~W} \mathrm{~kg}^{-1}$ is the background turbulent dissipation of a GM internal 140 wave spectrum at latitude $30^{\circ}$ in stratification $N_{0}=5.24 \times 10^{-3} \mathrm{rad} \mathrm{s}^{-1}$ [Garrett and Munk, 1975].

141 The absolute values of the Coriolis parameter at the latitude of interest $\left(67.6^{\circ} \mathrm{S}\right) \mathrm{f}$, and at $30^{\circ}\left(f_{0}\right)$ 142 were $1.34 \times 10^{-4} \mathrm{~s}^{-1}$ and $7.3 \times 10^{-5} \mathrm{~s}^{-1}$ respectively.

144 The function $h_{1}\left(R_{e}\right)$, which accounts for the dominant frequency in the observed wavefield, is 145 defined as:

$146 \quad h_{1}\left(R_{\omega}\right)=\frac{3\left(R_{\omega}+1\right)}{2 \sqrt{2} R_{\omega} \sqrt{R_{\omega}-1}}$

and is a function of the shear-to-strain ratio $R_{\omega}$ [Polzin et al., 1995]. In this study, we used the instances of concurrent RaTS CTD and moored ADCP data to estimate the time-evolving $R_{\omega}$. No clear seasonality in shear-to-strain ratios was observed, with the largest value of 20.6 occurring in May 2006 and the smallest value of 6.2 occurring in March 2005. The mean value for the measurement period was 11.2 , though we used the time-varying value in our calculations. We acknowledge that uncertainty in this parameter represents a significant source of uncertainty in our 
of $\sim 2$ ). Several papers in the Arctic have also shown that errors in $R_{\omega}$ can equate to significant deviations from microstructure-derived mixing rates (e.g. Wijesekera et al. [1993], Levine et al. [1987]).

Another important caveat to the parameterization is that we evaluated the vertical wavenumber shear spectra between wavelengths of $80 \mathrm{~m}$ and $130 \mathrm{~m}$ (in order to obtain a stable estimate of spectral power), but only calculated $N$ between the depths of $100 \mathrm{~m}$ and $200 \mathrm{~m}$, as the stratification of the upper $100 \mathrm{~m}$ was strongly affected by seasonal surface heat fluxes (which thus violates the conditions of the parameterization). An alternative approach would have been to use shorter integration limits for the shear (e.g. 25-100 m); however the resultant spectra were more strongly affected by high-frequency noise in this integration range and we thus considered those estimates less reliable than those obtained from the method chosen.

Finally, we also estimated the likely effect of instrumental noise on the shear variance spectra, to ensure that this did not significantly affect our estimate of $\varepsilon$ within the wavenumber limits of integration. The specified noise level of the ADCP specified by the manufacturer is $3 \mathrm{~cm} \mathrm{~s}^{-1}$, but inspection of individual velocity spectra (shown later in Fig. 5a) suggested the real noise floor was $\sim 2 \mathrm{~cm} \mathrm{~s}^{-1}$. Experimentation with a range of noise levels suggested no significant alteration in the spectral level until values of noise reach $\sim 6 \mathrm{~cm} \mathrm{~s}^{-1}$, which was much larger than our estimate of actual noise.

Diapycnal diffusivity (Fig. 2d) was estimated from the Osborn relationship as $\kappa=\Gamma \varepsilon / N^{2}$, where $\Gamma$ is the mixing efficiency, defining the ratio of the final change in potential energy relative to the kinetic energy lost (taken to be 0.2 [Oakey, 1982]). Note that this is strictly distinct from the dissipation flux coefficient $\Gamma_{d}$ [Osborn, 1980], though the two values are commonly assumed to be numerically equivalent. 
182 The vertical heat flux calculation (Fig. 2e) is detailed in Section 4.

In order to estimate the effect of double diffusion on turbulent mixing (a process which is not captured by the finescale parameterization outlined in Fig. 2b), density ratios and Turner angles were estimated for each CTD profile from January 2005 to April 2007. As vertical gradients of heat and salt generally have compensating effects on density in many RaTS profiles (cold and fresh surface water overlying warm and salty $\mathrm{CDW}$ ), one might expect the conditions for double diffusive layering [Schmitt, 1988] to be satisfied. The vertical inverse density ratio $R_{\rho}$, which expresses the relative importance of temperature to that of salinity in causing density change, is expressed as:

$$
R_{\rho}=\frac{\beta \partial_{z} S}{\alpha \partial_{z} T}
$$
where $\partial_{z} T$ is the vertical temperature gradient, $\partial_{z} S$ is the vertical salinity gradient and $\alpha$ and $\beta$ are the thermal expansion and haline contraction coefficients respectively. This value can alternatively be expressed as a Turner angle $T u$ [Ruddick, 1983], as follows:

$$
T u=\tan ^{-1} \frac{\left(\alpha \partial_{z} T+\beta \partial_{z} S\right)}{\left(\alpha \partial_{z} T-\beta \partial_{z} S\right)}
$$

Angles between $-90^{\circ}$ and $-45^{\circ}$ ( or $1<R_{\rho}<\infty$ ) indicate a temperature-destabilizing regime (liable to the development of well-mixed layers separated by sharp jumps in $T$ and $S$, strongest at values closest to 1$)$, whilst for $45^{\circ}<T u<90^{\circ}\left(0<\mathrm{R}_{\rho}<1\right)$ the water column is destabilized by salt and is susceptible to salt finger development. A variety of vertical difference widths (between $1 \mathrm{~m}$ and 
$50 \mathrm{~m}$ ) were used to test the sensitivity of the calculation to the choice of $T / S$ gradient; the value of

$T u$ was not significantly affected by this choice. Many of the profiles were characterized by $-90^{\circ}<$

$T u<-45^{\circ}$ (two representative examples in both summer and winter are shown in Fig. 3), implying

that the potential for double diffusive instability was present. During the period of the ADCP

deployment, 14 of the 88 profiles showed evidence of partially-developed thermohaline steps in the

211 pycnocline, typically less than $10 \mathrm{~m}$ in vertical extent (e.g. between $130 \mathrm{~m}$ and $200 \mathrm{~m}$ in Fig. 3a-c).

212 However, there was no clear evidence of seasonality in the prevalence of double diffusive activity

213 (fast-ice-covered vs. non-fast-ice covered periods). The stepped profiles had inverse density ratios

214 of between 3 and 5, implying relatively weak double diffusive layering (Fig. 3d,e). The vertical size

215 of the steps observed is similar to those found in the Palmer-Long Term Ecological Record time

216 series by Smith and Klinck [2002], who estimated that they were responsible for an upward heat

217 flux of up to $5 \mathrm{~W} \mathrm{~m}^{-2}$, and that they were important for maintaining upward heat fluxes during

218 winter whilst maintaining the water column stratification. However, in our data, there appeared to

219 be no clear preferential depth at which these features develop, and it was not clear whether they

220 have formed through in-situ diffusive processes or not. Instead, these features may have been

221 advected into Ryder Bay from Marguerite Bay to the south, or alternatively they may have formed

222 by mixing along the coastal boundary, with subsequent movement into the interior of the Bay.

From examination of the RaTS CTD data, we noted that these steps do not tend to persist from one profile to the next (a few days apart), implying that the structure was relatively quickly broken down by water column shear or other processes (if they are double diffusive at all). In line with other studies of this part of the WAP (e.g. Howard et al. [2004]), this implies that shear instability is the more important mixing mechanism as compared to double diffusion. However, this stands in contrast to the Weddell Sea, where double diffusive activity is more prevalent and contributes

230 significantly (up to $2 \mathrm{~W} \mathrm{~m}^{-2}$ ) to the diapycnal heat flux (e.g. Muench et al. [1990], Robertson et al. 231 [1995]). Whilst our time series data in Ryder Bay supports the notion that double diffusion is likely 
small compared with shear instability, higher-resolution time series measurements and more extensive CTD coverage within the Bay is required to confirm the mechanistic origin of these features. We thus do not consider these processes further in this study.

\subsection{Meteorological measurements}

Concurrent hourly time series of wind speed/direction and surface temperature were acquired from the meteorological station at Rothera, located $\sim 3 \mathrm{~km}$ east of the mooring deployment location (Fig. 1b). Daily observer estimates of sea-ice cover within Ryder Bay were made, based on type of ice

(brash, grease, pancake, pack, fast) and ice score (representing tenths of cover, from 0/10 to 10/10). Whilst the necessity of personnel changeover yielded some inter-observer variability, the interseasonal changes are much larger than these differences.

\section{Hydrographic context}

The annual and interannual hydrographic changes for the period 2005-2007 are shown in Fig. 4a-c. A full description of these data, as part of the full RaTS time series, is given in Venables and Meredith [2014]. Here we provide a brief summary of the characteristics pertinent to this study.

During the entire 2005-2007 period, the CDW was separated from the overlying, seasonally-variant AASW by a permanent halocline located between $100 \mathrm{~m}$ and $200 \mathrm{~m}$ (Fig. 4b). During each summer, a relatively shallow thermocline developed due to short wave solar input from the surface (Fig. 4a); the depth of this thermocline differed between the three years with deeper penetration of heat in 2006 and 2007 compared with 2005. This process was accompanied by the production of a seasonal halocline through local ice melt (Fig. 4b). By early March, sensible heat losses reduced the nearsurface temperature, but the maximum in temperature at $50 \mathrm{~m}$ did not occur until April/May. As 
summer transitioned into autumn, large sensible and latent heat losses drove the formation of winter 259 mixed layers, which reached up to $100 \mathrm{~m}$ in August 2005 and $\sim 70 \mathrm{~m}$ in August 2006 (Fig. 4a-c). In 260 addition, salinity increased as summer meltwater advects away and/or brine was rejected from 261 reforming sea ice (Fig. 4d). This refreezing process extracted the heat input into the water column 262 above the summertime temperature minimum. Periodically, this surface-driven mixing extended 263 sufficiently deep to cause heat loss from the CDW layer to the surface, though 2005-2007 were 264 characterized as years of generally shallow mixing, according to the analysis of Venables and 265 Meredith [2014]. This is an important factor when considering the use here of an internal wave266 based mixing parameterization, as it implies that direct convective processes do not strongly affect the 100-200 m layer.

The overall current structure within Ryder Bay is much less well understood, and this remains an important source of uncertainty in this study as it means the role of advective heat fluxes is largely unknown. Low-pass filtering the current meter data at 3 days and averaging over the length of the time series yielded a small residual mean flow, which peaked at $\sim 3 \mathrm{~cm} \mathrm{~s}^{-1}$ at $90 \mathrm{~m}$, and was oriented towards the northeast, with smaller velocities at deeper and shallower levels. The Bay may be affected during the summer and autumn months by the Antarctic Peninsula Coastal Current (APCC), which runs northeast to southwest along the west coast of Adelaide Island (Fig. 1) with a volume transport of $\sim 0.32 \mathrm{~Sv}$ [Moffat et al., 2008], peak velocities of $0.3-0.4 \mathrm{~m} \mathrm{~s}^{-1}$ and a freshwater transport of $126 \pm 50 \mathrm{~km}^{3} \mathrm{yr}^{-1}$. However, the routes of the current within Marguerite Bay itself remain unclear, so it was not easy to ascertain whether the small observed residual current was part of this system. Details of the dominant modes of current variability within the Bay (primarily resulting from winds and diurnal tides) are detailed in Section 5.1.

\section{Time series of inferred diffusivity and heat fluxes}


284 The time series of $\left\langle V_{z} / N>^{2}\right.$, and estimated $\varepsilon$ and $\kappa$ in the depth range 100-200 $\mathrm{m}$ are shown in Fig. $2852 \mathrm{~b}-\mathrm{d}$. Indicated on the figures are periods covered by full fast ice and those that are not (hereafter 286 referred to as 'fast-ice-free'). There was both seasonal and interannual variability in the time series, 287 with minimum values of $\left\langle V_{z} / N\right\rangle^{2}$ and $\varepsilon$ typically occurring during periods of fast ice cover (Fig. 288 2b,c), particularly in winter 2006. In contrast, elevated (but more variable) values of $\left\langle V_{z} / N\right\rangle^{2}$ and $\varepsilon$ 289 occurred when fast ice was absent, with significant maxima occurring in February and April 2005, 290 May to June 2006 and March to April 2007. Comparing mean $\varepsilon$ values for the fast-ice-covered and 291 fast-ice-free periods of 2006 for example, yielded values of $3.38 \times 10^{-9} \mathrm{~W} \mathrm{~kg}^{-1}$ and $5.04 \times 10^{-}$ ${ }^{9} \mathrm{~W} \mathrm{~kg}^{-1}$ respectively. Peaks in January 2005 and 2007 appeared to be associated with wind acting on the water column before the formation of summertime stratification (see Section 5 for more details of mechanisms). Converting the $\varepsilon$ values into $\kappa$ using the Osborn relationship yielded a more complex pattern, largely because of the effect of enhanced summertime stratification compared with wintertime values. Elevated $\kappa$ was still observed in May to June 2006 and March to April 2007, but, in general, the periods of low mixing during the fast-ice-free season were not strongly different to those with fast ice present, when measured using $\kappa$. The pattern was controlled by the interplay of short-term changes of internal wave shear (e.g. the large maxima in May to June 2006 in Fig. 2b) and seasonal changes in stratification $\left(N^{2}\right.$ increased shortly after the start of each summer season 301 (Fig. 4c) due to surface heating and ice melt [Venables and Meredith, 2014]). Two particular periods of enhanced diffusivity were observed in May to June 2006 and March to April 2007. Each of these appeared to be associated with enhanced wind stresses (see Section 5 below) that injected near-inertial shear into the water column. The missing values during December 2005 were due to a deep-drafted iceberg ( $80 \mathrm{~m}$ deep) occupying the site, causing spurious ADCP returns. These data were thus excluded. 


$$
Q=-\rho_{0} c_{p} \kappa \frac{\partial \theta}{\partial z}
$$

312 where $\rho_{0}$ is the reference density $\left(1025 \mathrm{~kg} \mathrm{~m}^{-3}\right), c_{p}$ is the specific heat capacity at constant pressure $313\left(4000 \mathrm{~J} \mathrm{~kg}^{-1}{ }^{\circ} \mathrm{C}^{-1}\right), \theta$ is the potential temperature and $\mathrm{\kappa}$ is the diapycnal diffusivity. A time series of 314 mean $Q$ between $100 \mathrm{~m}$ and $200 \mathrm{~m}$ is shown in Fig. 2e, estimated using the mean temperature 315 gradient between these depth horizons and a two-weekly smoothed $\kappa$ interpolated onto the times of 316 the RaTS CTD profiles. Changes in $Q$ in this depth range were largely governed by variability in $\kappa$, 317 as the mean temperature gradient only varied by a factor of two (from $0.008^{\circ} \mathrm{C} \mathrm{m}^{-1}$ to $0.019^{\circ} \mathrm{C} \mathrm{m}^{-1}$ ), 318 whilst $\kappa$ varied by an order of magnitude (from $0.1 \times 10^{-4} \mathrm{~m}^{2} \mathrm{~s}^{-1}$ to $2 \times 10^{-4} \mathrm{~m}^{2} \mathrm{~s}^{-1}$ ). The mean 319 upward heat flux was $\sim 1 \mathrm{~W} \mathrm{~m}^{-2}$, with the largest values of $\sim 2 \mathrm{~W} \mathrm{~m}^{-2}$ generally occurring early in 320 each summer season. Nevertheless, heat fluxes exceeding $0.5 \mathrm{~W} \mathrm{~m}^{-2}$ were observed year round (Fig. $3212 \mathrm{e}$ ), implying that a source of shear was present in all months of the year. Wintertime values did sometimes exceed the lowest summertime values, though most of the largest values $\left(>1.5 \mathrm{~W} \mathrm{~m}^{-2}\right)$ occurred in the fast-ice-free months, particularly at the beginning of each fast-ice-free period. These early summertime maxima were brought about through the alignment of three separate processes: the relatively strong velocity shear that occurred during the fast-ice-free season, the relatively weak stratification that occurred before surface temperatures have risen and ice melt had freshened the surface layers (Fig. 4a,b), and the relatively strong negative 100-200 $\mathrm{m}$ temperature gradient.

Assuming a latent heat of melting of sea ice of $2.92 \times 10^{5} \mathrm{~J} \mathrm{~kg}^{-1}$ (for a sea ice salinity of 5) and $Q=1.0 \mathrm{~W} \mathrm{~m}^{-2}$, the upward flux of heat from the CDW layer could melt $\sim 0.11 \mathrm{~m}$ of sea ice over one 331 year. The total annual formation rate is estimated as 1.9-2.9 $\mathrm{m}$ [Venables and Meredith, 2014].

332 Changes in the diapycnal diffusivity in response to reducing sea-ice extent may therefore have a small positive feedback on the rate of sea-ice loss, though other significant processes are also at play here. For example, the heat content in the upper $200 \mathrm{~m}$ is dominated primarily by surface fluxes (and possibly also lateral advection), meaning that effects of reducing sea ice are likely to be 
modest. Changes would be most likely to occur in response to enhanced wind stress on the ocean surface promoting an increase in near-inertial shear during the winter months when the water column stratification is already relatively low. However, other feedbacks also have to be taken into account, such as the so-called thermal barrier effect [Martinson and Ianuzzi, 2008], which contends that the heat content of the halocline acts to stabilize the water column by its ability to melt sea ice. In the following section, we document the controls on mixing during both winter and summer seasons and identify the extent to which tides and winds may promote shear instabilities in the zone between the CDW and AASW.

Howard et al. [2004], who invoked an alternative Richardson Number-based parameterization of mixing, estimated that heat fluxes in Marguerite Bay during the autumn of 2001 were smaller than $2 \mathrm{~W} \mathrm{~m}^{-2}$. In addition, they found that double diffusive processes make only a small contribution to the heat flux $\left(0.2-0.4 \mathrm{~W} \mathrm{~m}^{-2}\right)$. Smith and Klinck [2002], in contrast, estimated larger shelf-averaged double diffusive heat fluxes of $5 \mathrm{~W} \mathrm{~m}^{-2}$, but did not consider the role of shear instability in detail. In addition, Ross and Lavery [2010] reported a dissipation rate of $10^{-9} \mathrm{~W} \mathrm{~kg}^{-1}$ farther north on the Peninsula (between Renaud and Anvers Islands), which is a similar order of magnitude to our 352 results.

\section{Controls on Mixing}

Wind-driven near-inertial motions [Howard et al., 2004] and locally-generated internal tides

357 [Wallace et al., 2008] have both been proposed as potential mixing mechanisms at the RaTS site. In 358 this section we isolate the dominant processes and investigate how these contribute to the observed seasonality and variability both in heat fluxes and $\kappa$. 
363 Mean power spectra (Welch estimation, 8 Hamming windows of 30-40 days, 50\% overlap) for $u$ 364 and $v$ velocities in the top $200 \mathrm{~m}$ are displayed in Fig. 5a-d for deployment periods 1 and 2, and 365 divided into periods with and without fast ice cover. The most significant peak is centered on the 366 diurnal frequencies (K1 and O1), with smaller secondary semidiurnal peaks (M2/S2). Harmonic 367 analysis (using t-tide) of these velocities (Fig. 6a-c) revealed K1 and O1 tides with similar 368 structures [Foreman, 1978; Pawlowitz et al., 2002]. The combined barotropic plus baroclinic 369 component of K1 and O1 (Fig. 6a,b) had a minimum major-axis magnitude of $0.4 \mathrm{~cm} \mathrm{~s}^{-1}$ around $37060 \mathrm{~m}$ depth $\left( \pm 0.3 \mathrm{~cm} \mathrm{~s}^{-1}\right)$, increasing to $\sim 1 \mathrm{~cm} \mathrm{~s}^{-1}\left( \pm 0.3 \mathrm{~cm} \mathrm{~s}^{-1}\right)$ at 150-200 m. In addition, there 371 were a number of clear phase reversals in both diurnal and semidiurnal tides (Fig. 6d-f), suggesting 372 the presence of complex internal tides. Note that for many of the periods of data that we analyzed 373 (e.g. the fast-ice-free parts of all three years, and the fast-ice-covered part of 2006), the time period 374 was not sufficiently long to separate out the K1 tide (23.93 h) from P1 (24.07 h). However, 375 harmonic analysis of those periods that were sufficiently long to separate out K1 and P1 (e.g. the 376 whole Year 1 deployment) revealed relatively weak P1 tidal velocities $\left(0.3 \pm 0.2 \mathrm{~cm} \mathrm{~s}^{-1}\right)$ that were 377 largely barotropic, implying that P1 tides were not as significant as O1/K1 in shear generation. 378 However, we acknowledge the signal-to-noise ratio here was low.

380 The magnitude of the tidal velocities was generally higher in the fast-ice-free season, with peak 381 diurnal tidal velocities exceeding $1.5 \mathrm{~cm} \mathrm{~s}^{-1}$ during the fast-ice-free part of 2005 . However, the 382 magnitudes of the M2 tidal velocities were much weaker (Fig. 6c) and less depth-variant (maximum 383 values $<0.6 \mathrm{~cm} \mathrm{~s}^{-1}$ ), suggesting tides of this frequency only provided a weak source of shear. Whilst 384 the average shear magnitude of even the diurnal tides was modest, there were periods within the 385 time series where tidal shears were significantly larger over portions of the water column than the 386 average values suggest, being comparable with the local values of $N^{2}$. This means that diurnal tides 
likely sustained a weak upward flux throughout the months when fast-ice was present at the site,

388 though the largest upward fluxes of heat were not observed at these times (Fig. 2e).

390 The orientation of the tidal ellipses for K1 and O1 was generally east-west, reflecting the movement

391 of water into and out of the bay, with a general preference (though not exclusively) for the tidal

392 ellipses to be counter-clockwise oriented (Fig. 6e,f). Note that the K1 tide has a longer period

$393(23.93 \mathrm{~h})$ than the local inertial period $(12.95 \mathrm{~h})$, implying that any tidal shear generated at these

394 frequencies will not be freely propagating. However, as previously outlined by Wallace et al.

395 [2008], there are sufficient local generation sites close to Rothera for the K1 barotropic tide to

396 excite baroclinic waves (their Fig. 14).

Decomposing the mooring velocity spectra into its rotary components (Fig. 7a,b) revealed that, during the fast-ice-free months, there was a significant enhancement of rotation of both senses at all depths compared with the fast-ice-covered months (as denoted by the more intense green/orange colours in Fig. 7a,b compared with 7c,d). However, the counterclockwise (CCW) rotation was enhanced more strongly than the clockwise $(\mathrm{CW})$. This enhancement was particularly strong around the inertial frequency. In contrast, during the fast-ice-free months, the difference between CCW and 404 CW was much smaller (Fig. 7c,d). This pattern is shown more clearly in the rotary coefficient plot 405 (Fig. 8a), which expresses the ratio of clockwise to counterclockwise energy in the ADCP data 406 (technically $\log _{10}(\mathrm{CW} / \mathrm{CCW})$ ). This ratio exhibited large negative values during the fast-ice-free 407 season, particularly between 0.9 and $1.5 f$ (Fig. 8b). Furthermore, these peaks generally 408 corresponded to observed maxima in local wind speed (e.g. in May, June and July 2006, Fig. 8c, but 409 also in February and March 2005 - not shown). Correlation statistics between the wind stress and 410 rotary coefficient are presented below. 
412 To illustrate the relative importance of wind and diurnal tidal forcing in generating water column

413 shear, Figs. 8d and 8e show band-pass filtered current speeds for the second deployment period for 414 the near-inertial and diurnal bands respectively. Near-inertial velocities in the fast-ice-free season 415 (Fig. 8d) peaked at 3-5 $\mathrm{cm} \mathrm{s}^{-1}$, with the strongest velocities coinciding with the periods of strongest 416 local wind speeds (Fig. 8c). At these times, the strongest near-inertial velocities were concentrated 417 in the near-surface layers, but commonly penetrated beyond $150 \mathrm{~m}$ depth (e.g. in April, May and 418 July 2006). These velocities were significantly weaker in the fast-ice-covered season (generally 1$4193 \mathrm{~cm} \mathrm{~s}^{-1}$ ) and showed no direct correlation with the wind field. In comparison, the diurnal tidal 420 current speeds (Fig. 8e) were significantly weaker (typically $1-2 \mathrm{~cm} \mathrm{~s}^{-1}$ ), with a pronounced 13.5 421 day signal (associated with the spring-neap cycle of $\mathrm{K} 1+\mathrm{O} 1$ ). Tidal velocities were also suppressed 422 in the ice-free season (as previously observed in Fig. 6), most likely due to stratification changes 423 within the water column (Fig. 4c).

This dominance of $\mathrm{CCW}$ rotation was concentrated at frequencies slightly higher than the inertial frequency, but was apparent across a broad range from 0.9-1.7 $f$ (see blue shading in Fig. 8a). This suggests a significant input of near-inertial wind energy into the water column that is strongly suppressed during periods of fast ice within Ryder Bay. The reason for the CCW energy being concentrated at frequencies slightly higher than the inertial is likely to be the strong summertime stratification and likely small horizontal wavenumber of near-inertial waves (Ryder Bay is only

$43110 \mathrm{~km}$ wide). Following Pollard [1970], the frequency of near-inertial waves, $\sigma$, is expressed as $\sigma=f\left(1+k^{2} N^{2} / f^{2} n^{2}\right)^{0.5}$, where $k$ is the horizontal wavenumber of the wave and $n$ is the vertical 433 wavenumber for the relevant mode. Assuming $k=6.28 \times 10^{-4} \mathrm{~m}^{-1}$ (corresponding to a horizontal 434 scale of $10 \mathrm{~km}$, the approximate diameter of Ryder Bay), $n=0.0628 \mathrm{~m}^{-1}$ (corresponding to a 435 vertical scale of $100 \mathrm{~m}$ ) and $N^{2}=1 \times 10^{-4} \mathrm{~s}^{-1}$ (Fig. $4 \mathrm{c}$ ), $\sigma=1.24 f$ or $\sim 10.5 \mathrm{~h}$. This estimate matches 436 well with the observed frequency of maximum CCW polarization during fast-ice-free periods. In 437 further support of this interpretation is the fact that, when a near-inertial peak was observed during 
the ice-covered months (e.g. in September 2006) possibly through propagation of energy from nearby regions with less ice cover, the frequency of maximum $\mathrm{CCW}$ polarization was closer to $f$, because of the weaker stratification during the winter months $\left(\sim 5 \times 10^{-5} \mathrm{~m}^{2} \mathrm{~s}^{-1}\right.$, Fig. $\left.4 \mathrm{c}\right)$. This alters the effective frequency of near-inertial waves to $\sim 1.13 f$ or a period of $11.5 \mathrm{~h}$, which corresponds well to the observed peak in CCW energy at that time.

An alternative interpretation for the increased $\mathrm{CCW}$ polarization during periods without fast ice would be a change in the polarization of the M2 tidal component. However, examination of the tidal ellipses into their CW- and CCW-rotating components (Fig. 6d-f) revealed no large changes in tidal polarization on a seasonal basis (the tidal shear was actually less CCW-polarized during fast-icefree periods). The enhanced CCW rotation during periods without fast ice was clearly evident when the rotary coefficients $\left(\log _{10}(\mathrm{CCW} / \mathrm{CW})\right)$ were inspected (Fig. 8a). Even short periods of fast-icefree conditions (e.g. in early July 2006) showed strongly positive rotary coefficients. This implied that the spectral content of the internal wave field at the site was strongly dictated by local ice conditions, which, under favourable stratification (and temperature gradient) conditions, had a profound impact on turbulent diffusivity and vertical heat fluxes.

We then considered the extent to which the observed changes in rotary coefficient within the fastice-free season were determined by input of energy by the local winds. In both 2006 and 2007, there appeared to be a pattern of enhanced $\varepsilon$ at the start of the season, followed by reduced values in the middle of the summer season, and enhanced values again in April-May. Examining the time series suggested that this pattern was primarily caused by changing wind stress (as the strongest winds in both these years occurred at the start and end of the summer season). However, to test whether changing wind stresses did increase $\mathrm{CCW}$-polarized near-inertial energy in the water column, time series of wind stress $\tau=\rho C_{D} U^{2}$ (where $C_{D}$ is the drag coefficient and $\mathrm{U}$ is horizontal wind speed) 
current velocity during the fast-ice-free months. For this calculation, $U$ was low-pass filtered (with cutoffs varying between 0.5 and 10 days) and rotary coefficients at near-inertial frequencies were evaluated over a moving 30-day period during the fast-ice-free months. $C_{D}$ was calculated as $\frac{0.29+3.1 / U+7.7 / U^{2}}{1000}$ for wind speeds less than $6 \mathrm{~m} \mathrm{~s}^{-1}$ and $0.60+0.070 U_{10}$ for wind speeds greater than $6 \mathrm{~m} \mathrm{~s}^{-1}$ [Yelland and Taylor, 1996]. Note that although this is strictly an open ocean parameterization, the results were not sensitive to whether $C_{D}$ is calculated using his method, or prescribed as a fixed value.

\section{Correlations between local 10-day low pass filtered wind stress and rotary coefficient averaged} between 1 and $1.7 f$ were stronger during the fast-ice-free periods than during periods with fast ice present, with alignment of peaks in, e.g. May and July 2006 (Fig. 8b,c). However, the correlations only reached statistical significance at the $90 \%$ confidence level during the 2005 fast-ice-free season $(\mathrm{R}=-0.35, \mathrm{p}=0.06)$. The weakness of the correlation may reflect variations in the effectiveness of the transfer of momentum to the upper ocean in differing ice conditions and the fact that inertial motions are more effectively transmitted to the water column at times of sudden acceleration/deceleration in wind speed (see Section 5.2 below). In contrast, there was no correlation at the $90 \%$ confidence level between wind stress and rotary coefficient for periods when fast ice was present at the site, confirming that fast ice provided an effective barrier to the transmission of locally generated near-inertial motions into the water column. Full statistics are provided in Table 1.

To test whether inertial motions in the bay were responsive to winds integrated over a wider region than just the bay itself, the correlations were repeated using 7-day low pass filtered winds from ECMWF Interim Reanalysis for the period of the mooring deployment [Dee et al. 2011] (Fig. 8c). These winds were averaged over a one-degree box around the RaTS site. No significant correlations were found during fast-ice-covered or fast-ice-free seasons (Table 1). This suggests that near- 
490 inertial motions were largely responsive to local wind conditions and are not generated in distant

491 regions (>100 km away) with subsequent propagation into Ryder Bay.

\subsection{Shear spectra and analysis}

Power spectra of the shear variance time series (from which the time series of $\varepsilon$ and $\kappa$ were derived) are displayed in Fig. 9. During the period of study, there was a clear modulation at O1 and K1 tidal frequencies, primarily due to the baroclinic nature of the tide outlined in Section 5.1. No other statistically significant peaks appeared, but there was a difference in spectral shape between periods with and without fast ice cover. Periods without fast ice had higher spectral power at all periods between the subinertial (10 days) and $\sim 3 \mathrm{cpd}$, with particular enhancement close to (and at

501 frequencies slightly higher than) the inertial frequency, as far to $2 f$ in $2005 / 6$, and as far as $4 f$ in 2006 and 2007 (Fig. 9a,b). This was consistent with the velocity spectra and implies that there was significantly stronger near-inertial shear during periods when the site is fast-ice-free.

To illustrate the processes occurring more clearly, we focused on the $u$ and $v$ wind, ADCP velocities and shear vectors for the ten-day period around 24 May 2006 (Fig. 10), when $\varepsilon$ was particularly large $\left(2.3 \times 10^{-8} \mathrm{~W} \mathrm{~kg}^{-1}\right)$. In particular, we considered the magnitude and direction of shear between the depth ranges of 0-100 $\mathrm{m}$ and 100-200 m. During two periods when the shear variance (as quantified by the finescale parameterization) was strongly enhanced (around 20 May

510 and 24 May), there were very strong velocity shears between the surface layer (down to 80 to

$511100 \mathrm{~m}$ ) and the underlying waters. These shears rapidly alternated (Figs. 10a and 10b), and the 512 shear vector moved through $360^{\circ}$ every inertial period (Fig. 10b).

514 This was a period of highly variable wind stress forcing (Fig. 10c-d), which began with a westerly 515 wind rotating in a cyclonic direction, ultimately producing a peak in northeastward wind stress by 
20 May (with wind speeds exceeding $22 \mathrm{~m} \mathrm{~s}^{-1}$ ). Over the next four days, the wind stress first

517 rotated anticyclonically back to the northwest and then weakened. Between 24 May and 27 May,

518 there followed a period of strongly variable winds, alternating between northerly wind speeds of

$519 \sim 10 \mathrm{~m} \mathrm{~s}^{-1}$ and southerlies of a similar magnitude over the course of just a few hours. Over the same

520 period, the wind acquired an easterly component (Fig. 10c). These strong and highly variable

521 stresses appear to be particularly effective at generating near-inertial motion (and shear), promoting 522 enhanced turbulence and vertical mixing (as shown through the high values of $\varepsilon$ at this time). This 523 is shown clearly in the shear direction plot (Fig. 10b), which exhibited CCW motion of periods of $524 \sim 12$ hours on 20,21, 23, 24, 26 and 28 May, as shown by the sloping black lines. This CCW motion 525 was commonly intermittent (e.g. on 26 and 28 May), possibly owing to the presence of nearby 526 lateral boundaries within Ryder Bay, but sometimes was present over several inertial periods (e.g. on 23 and 24 May). There was no obvious relationship between the direction of rotation of the wind vector and the response in shear variance, either in this example or in other periods of enhanced shear.

This contrasts strongly with periods in the time series when fast ice was present (Fig. 11). During those periods, the magnitude of $\varepsilon$ was typically weaker, and the shear that did exist tended to be driven primarily by the $\mathrm{K} 1$ and $\mathrm{O} 1$ internal tides discussed previously. This can be seen in Fig. 11a for the period 4 June to 13 June 2005. This was a period of very low shear variance and $\varepsilon$ (Fig. $2 \mathrm{~b}, \mathrm{c})$, with the lowest values centered on 10 June. During this period, the transmission of nearinertial activity from the wind was blocked by the presence of fast ice at the site and, as a result, no clear correlation was seen between either $u$ or $v$ wind (Figs. 11c,d) and the magnitude of $\varepsilon$. Instead, the dominant source of shear in the water column was related to a baroclinic tide of diurnal period (Figs. 11a,b), which typically had weaker velocities than the near-inertial motions. At this period of 540 the time series, this produced clear CCW rotation of period close to 24 hours. After 11 June, this became a $\mathrm{CW}$ rotation, due to the changing phase of the $\mathrm{O} 1$ and $\mathrm{K} 1$ tides. 
543 No clear correlation was seen between either $u$ or $v$ wind and the magnitude of $\varepsilon$ between 4 and 13

544 June. Therefore, it is probable that the diurnal tide sustained weaker mixing when wind forcing was 545 absent, through a cascade of this subinertial energy to higher frequencies, where it ultimately breaks 546 down as turbulence.

\section{Conclusions and Implications}

Through analysis of a 2.5 year time series of ADCP data, combined with co-located CTD and wind measurements, a clear difference was observed in the controls on diapycnal mixing between periods when fast ice was present at this site on the West Antarctic Peninsula and when it was absent.

553 Whilst shear variance during the fast-ice-covered season was modulated dominantly by diurnal tidal 554 motions (dominantly $\mathrm{K} 1$ and $\mathrm{O} 1$ ), a broad increase in near-inertial kinetic energy and near-inertial shear was observed during the fast-ice-free period, which is consistent with wind-forced motions being a significant additional source of shear in the water column. This conclusion was supported by the observed correlation between CCW motions throughout the upper $200 \mathrm{~m}$ of the water 558 column and observed wind speeds at the site, with a case study at the site (Section 5.2) suggesting that the strongest mixing events might be triggered by rapid changes in wind speed/direction that provide the necessary instantaneous acceleration for the generation of near-inertial internal waves

561 and shear.

563 This result has important implications in the context of the rapid environmental changes that are 564 occurring around the Peninsula. Venables and Meredith [2014] already postulated that years with 565 reduced winter fast ice were subject to increased mixing and a concomitant reduction in 566 stratification during the following summer. During the period 2005-2007, there was no statistically 567 significant difference in upward heat flux between winter and summer seasons, because the 
increased mechanical energy input to the water column during summer was offset by the stronger summertime stratification and a less favourable temperature gradient during that period (Fig. 4a,c). However, the rapid reduction in sea-ice duration in recent years will allow more mechanical energy input at a period of the year when the direction of the surface heat flux is reversed (i.e. ocean to atmosphere) and when stratification is significantly weaker due to the erosion of the strong summertime halocline. This may mean that direct deep mixing events, such as those observed by Venables and Meredith [2014] during 2008-2013, are likely to become more common. In addition, the increase in storm activity on the shelf through the persistent positive SAM index [Lefebvre et al., 2004; Thompson and Solomon, 2002] might further increase the mechanical energy available for turbulent mixing. An increase in $\kappa$ may also significantly impact the fluxes of important nutrients from the CDW (e.g. nitrate) into the surface water layers.

Whilst we have identified two important mechanisms controlling turbulent mixing, a number of questions remain unanswered that will be addressed in future work. A significant source of uncertainty in this study is the use of the finescale shear-based parameterization to determine $\varepsilon$.

583 Much improved estimates of diapycnal diffusivity and heat fluxes will be available once comprehensive microstructure data are available for this region, which will also allow us to assess the role of double diffusive processes in more detail. Secondly, we are not clear how representative processes at this site are of conditions on the wider shelf. For instance, we note that tidal velocities within Ryder Bay are particularly weak; climatic changes in water column stratification in regions 588 of the shelf with stronger tides (e.g. near the shelf break) may impact the structure of internal tides leading to a change in tidally-driven mixing. Finally, the alteration in sensible heat fluxes due to 590 changes in wintertime atmospheric temperatures, which have increased by $1^{\circ} \mathrm{C}$ per decade [Turner 591 et al., 2005], will also be a strong control on ocean-to-atmosphere fluxes and upper ocean 592 stratification. These will all need to be quantified and understood fully to predict the climatic and 593 ecological consequences of future heat flux changes in the Antarctic surface waters. 
Acknowledgments

We thank everyone concerned with the collection and provision of data used here. These include the series of Rothera Marine Assistants who have spent up to two years on base collecting the CTD data and numerous other staff who have supported the RaTS programme, both at Rothera and in Cambridge. Dr. Mags Wallace is particularly thanked for her early work with the moorings data.

We also acknowledge Dr. Laurie Padman and an anonymous reviewer for their extensive comments that have significantly improved the manuscript. This work is a contribution of the BAS Polar

Oceans Programme, funded by the Natural Environment Research Council. Brearley is funded by a NERC Independent Research Fellowship (NE/L011166/1).

\section{References}

Clarke, A., Meredith, M.P., Wallace, M.I., Brandon, M.A., Thomas, D.N., 2008. Seasonal and interannual variability in temperature, chlorophyll and macronutrients in northern Marguerite Bay, Antarctica. Deep Sea Res. II 55, 1988-2006.

611 Cook, A.J., Fox, A.J., Vaughan, D.G., and Ferrigno, J.G., 2005. Retreating glacier fronts on the 612 Antarctic Peninsula over the past half-century. Science 308, 541-544.

614 Cook, A.J., Vaughan, D.G., Luckman, A.J., Murray, T., 2014. A new Antarctic Peninsula glacier 615 basin inventory and observed area changes since the 1940s. Antarctic Science 26(6), 614-624. 
620 Hersbach, H., Holm, E.V., Isaksen, L., Kallberg, P., Kohler, M., Matricardi, M., McNally, A.P., 621 Monge-Sanz, B.M., Morcette, J.-J., Park, B.-K., Peubey, C., de Rosnay, P., Tavolato, C., Thepaut, 622 J.-N., Vitart, F., 2011. The ERA-Interim reanalysis: configuration and performance of the data 623 assimilation system. Quart. Journal R. Met. Soc. 137 (656), 553-597.

Foreman, M.G.G., 1978. Manual for tidal currents analysis and prediction. Tech. Rep. Pacific Marine Science Report 78-6. Institute of Ocean Sciences. Patricia Bay. Sidney, B.C.

Garrett, C., Munk, W., 1975. Space-time scales of internal waves_-Progress report. J. Geophys.

Gregg, M.C., Sanford, T.B., Winkel, D.P., 2003. Reduced mixing from the breaking of internal

Howard, S.L., Hyatt, J., Padman, L., 2004. Mixing in the pycnocline over the western Antarctic

Hyatt, J., Beardsley, R.C., Owens, W.B., 2011. Characterization of sea ice cover, motion and

641 Oceanic heat delivery via Kangerdlugssuaq Fjord to the south-east Greenland ice sheet, J. Geophys.

644 Klinck, J.M., Dinniman, M.S., 2010. Exchange across the shelf break at high southern latitudes, 645 Ocean Sci. 6, 513-524. 
647 Lefebvre, W., Goosse, H., Timmerman, R., Fichefet, T., 2004. Influence of the Southern Annular 648 Mode on the sea ice-ocean system. J. Geophys. Res. 109 (C09005), doi:1 0.1029/2004JC002403. 649

650 Levine, M., D., Paulson, C.A., Morrison, J.H., 1987. Observations of internal gravity waves under 651 the Arctic pack ice. J. Geophys. Res., 92, C1, 779-782.

653 Marshall, G. J., 2003. Trends in the southern annular mode from observations and reanalyses. J.

654 Clim., 16, 4134-4143.

656 Martinson, D.G., McKee, D.C., 2012. Transport of Upper Circumpolar Deep Water onto the 657 western Antarctic Peninsula continental shelf. Ocean Sci. 8, 433-442, doi:10.5194/os-8-433-2012. 658 659 Meredith, M.P., King, J.C., 2005. Rapid climate change in the ocean west of the Antarctic 660 Peninsula during the second half of the twentieth century. Geophys. Res. Lett. 32, L19604, 661 doi:10.1029/2005GL024042.

662

663 Meredith, M.P., Wallace, M.I., Stammerjohn, S.E., Renfrew, I.A., Clarke, A., Venables, H.J., 664 Shoosmith, D.R., Soutser, T., Leng, M.J., 2010. Changes in the freshwater composition of the upper 665 ocean west of the Antarctic Peninsula during the first decade of the $21^{\text {st }}$ century. Prog. Oceanogr. $66687,127-143$.

667

668 Moffat, C., Beardsley, R.C., Owens, B, van Lipzig, N., 2008. A first description of the Antarctic 669 Peninsula Coastal Current. Deep Sea Res., 55, 277-293. 
671 Moffat, C., Owens, B., Beardsley, R.C., 2009. On the characteristics of Circumpolar Deep Water 672 intrusions to the west Antarctic Peninsula continental shelf. J. Geophys. Res. 114, C05017, 673 doi:10.1029/2008JC004955.

674

675 Muench, R.D., Fernando, H.J.S., Stegen, G.R., 1990. Temperature and salinity staircases in the 676 Northwestern Weddell Sea, J. Phys. Oceanogr., 20, 295-306.

678 Oakey, N.S., 1982. Determination of the rate of dissipation of turbulent energy from simultaneous 679 temperature and velocity shear microstructure measurements. J. Phys. Oceanogr. 12, 256-271. 680 681 Osborn, T.R., 1980. Estimates of the local rate of vertical diffusion from dissipation measurements, 682 J. Phys. Oceanogr. 10, 83-89.

683

684 Padman, L., Howard, S. and Muench, R., 2006. Internal tide generation along the South Scotia 685 Ridge. Deep-Sea Res. II 53 (1-2), 157-171.

686

687 Pawlowitz, R., Beardsley, B. and Lentz, S., 2002. Classical tidal harmonic analysis including error 688 estimates in MATLAB using t_tide. Computers and Geosciences 28(8), 929-937. 689

690 Pollard, R.T., 1970. On the generation by winds of inertial waves in the ocean. Deep-Sea Res. 17, $691 \quad 795-812$.

692

693 Polzin, K., Toole, J.M., Schmitt, R.W., 1995. Finescale parameterizations of turbulent dissipation. 694 J. Phys. Oceanogr. 25, 306-328. 
Polzin, K., Kunze, E., Hummon, J., Firing, E., 2002. The finescale response of lowered ADCP

697 velocity profiles, J. Atm. Ocean. Tech. 19, 205-224.

698

699 Pritchard, H. D., Ligtenberg, S.R.M., Fricker, H.A., Vaughan, D.G., van den Broeke, M.R., 700 Padman, L., 2012. Antarctic ice-sheet loss driven by basal melting of ice shelves, Nature $701 \quad 484(7395), 502-505$.

702

703 Rainville, L., Woodgate, R.A., 2009. Observations of internal wave generation in the seasonally 704 ice-free Arctic. Geophys. Res. Lett. 36, L23604, doi:10.1029/2009GL041291.

Rignot, E., Jacobs, S., Mouginot, J., Scheuchl, B., 2013. Ice-shelf melting around Antarctica,

\section{8}

Ross, T., Lavery, A., 2010. Acoustic detection of oceanic double-diffusive convection: a feasibility study. J. Atmos. Oc. Tech., 27(3), 580-593.

Robertson, R., Padman, L., Levine, M.D., 1995. Fine structure, microstructure and vertical mixing processes in the upper ocean in the western Weddell Sea. J. Geophys. Res., 100, C9, 18517-18535. activity. Deep-Sea Res. 30, 1105-1107.

Schmitt, R.W., 1988. Mixing in a thermohaline staircase, in Small-Scale Turbulence and Mixing in 719 the Ocean, edited by Nihoul, J.C.J. and Jamart, B.M., pp. 435-452, Elsevier, New York. 
721 Smith, D.A., Klinck, J.M., 2002. Water properties on the west Antarctic Peninsula continental shelf: 722 a model study of effects of surface fluxes and sea ice, Deep Sea Res II 49, 4863-4886.

724 Stammerjohn, S.E., Martinson, D.G., Smith, R.C., Iannuzzi, R.A., 2008a. Sea ice in the western 725 Antarctic Peninsula region: Spatio-temporal variability from ecological and climate change 726 perspectives. Deep Sea Res. II 55, 2041-2058.

728 Stammerjohn, S.E., Martinson, D.G., Smith, R.C., Yuan, X., Rind, D., 2008b. Trends in Antarctic 729 annual sea ice retreat and advance and their relation to El Niño-Southern Oscillation and Southern 730 Annular Mode variability. J. Geophys. Res. 113, C03S90, doi:10.1029/2007JC004269.

Straneo, F., Sutherland, D.A., Holland, D., Gladish, C., Hamilton, G., Johnson, H., Rignot, E., Xu, 733 Y., Koppes, M., 2012. Characteristics of ocean waters reaching Greenland's glaciers. Annals of 734 Glaciology 53(60), 202-210.

Thompson, D.W.J., Solomon, S., 2002. Interpretation of recent Southern Hemisphere climate 737 change. Science 296, 895-899.

739 Turner, J., Colwell, S.R., Marshall, G.J., Lachlan-Cope, T.A., Carleton, A.M., Jones, P.D., Lagun, 740 V., Reid, P.A., Iagovkina, S., 2005. Antarctic climate change during the last 50 years. Int. J. Clim. $741 \quad 25(3), 279-294$.

743 Valkonen, T., Vihma, T., Doble, B., 2008. Mesoscale modelling of the atmosphere over Antarctic 744 sea ice: A late autumn case study. Mon. Weather Rev., 136, 1457-1474. 
Venables, H.J., Clarke, A., Meredith, M.P., 2013. Wintertime controls on summertime stratification

747 and productivity at the western Antarctic Peninsula. Limnology and Oceanography 58, 1035-1047.

749 Venables, H.J., Meredith, M.P., 2014. Feedbacks between ice cover, ocean stratification and heat

750 content in Ryder Bay, western Antarctic Peninsula. J. Geophys. Res. Oceans 119, 5323-5336, doi:

$751 \quad 10.1002 / 2013 J C 009669$.

752

753 Wallace, M. I., Meredith, M.P., Brandon, M., Sherwin, T.J., Dale, A.C., Clarke, A., 2008. On the

754 characteristics of internal tides and coastal upwelling behaviour in Marguerite Bay, west Antarctic 755 Peninsula. Deep Sea Research II 55, 2023-2040, doi:10.1016/j.dsr2.2008.04.033.

Waterman, S., Polzin, K.L., Naveira Garabato, A.C., Sheen, K.L., Forryan, A., 2013. Suppression 758 of internal wave breaking in the Antarctic Circumpolar Current near topography, Journal of 759 Physical Oceanography, 44(5), 1466-1492.

Wijesekera, H., Padman, L., Dillon, T., Levine, M., Paulson, C., Pinkel, R., 1993. The application 762 of internal-wave dissipation models to a region of strong mixing. Journal of Physical 763 Oceanography, 23, 269-286.

Yelland, M., Taylor, P.K., 1996. Wind stress measurements from the open ocean. J. Phys.

766 Oceanogr. 26, 541-558.

Figures

770 Figure 1: (a) Location of Rothera station on the West Antarctic Peninsula shelf, with Marguerite 771 Trough indicated. $500 \mathrm{~m}$ and $1000 \mathrm{~m}$ isobaths from the International Bathymetric Chart of the 
Southern Ocean (IBCSO) are indicated; (b) Position of the RaTS mooring within Ryder Bay. The location of the British Antarctic Survey base at Rothera, from which the meteorological and ice observations were collected, is marked. The CTD measurements, acquired at roughly two-week intervals, were made as close as practicable to the mooring location (see Venables et al. [2014]). Bathymetry is indicated.

Figure 2: (a) Example buoyancy-normalized shear spectra calculated over the top $200 \mathrm{~m}$ of the water column for March 2005, without the Polzin et al. [2002] corrections applied. The wavenumber integration limits used in the finescale parameterization are marked with vertical dashed lines, and the GM spectrum is also indicated with the horizontal dashed line; (b) Daily time series of buoyancy-normalized shear variance $\left\langle V_{z} / N\right\rangle^{2}$, integrated between $80 \mathrm{~m}$ and $130 \mathrm{~m}$. Periods of fast ice cover are marked with gray bars. Note the general enhancement during periods when fast ice is absent; (c) Daily time series of turbulent kinetic energy dissipation rate $\varepsilon$ (in $\mathrm{W} \mathrm{kg}^{-}$ ${ }^{1}$ ) between 100 and $200 \mathrm{~m}$ depth computed using the Gregg et al. [2003] parameterization described in the text; (d) Daily time series of the diapycnal diffusivity $\kappa$ in the same depth range. Note that the seasonality was less pronounced as the higher shear during the ice free periods was compensated to some degree by the increased stratification compared with the winter months; (e) Time series of vertical heat flux (positive upwards) estimated from two-weekly averaged $\kappa$ and the mean vertical temperature gradient between $100 \mathrm{~m}$ and $200 \mathrm{~m}$ from the RaTS CTD measurements. Values were generally enhanced at the start of each ice-free period and in June 2006 and March/April 2007.

Figure 3: Examples of possible double diffusive activity within RaTS CTD profiles. Panels (a), (b) and (c) show example raw summer (red) and winter (blue) potential temperature, salinity and potential density profiles. The summer (red) profile was from 24 January 2006, whilst the winter (blue) profile was from 17 September 2005. Partially developed step-like features of vertical scale 5-10 $\mathrm{m}$ were found between $130 \mathrm{~m}$ and $200 \mathrm{~m}$ depth in each profile. These features corresponded to 
inverse density ratios (panel d) of around 3-5 (or Turner angles (panel e) of around $-60^{\circ}$ ),

suggesting relatively weak double diffusive convection may be present. However, these steps did not seem to persist between profiles separated by a few days, suggesting that they are broken down relatively rapidly by shear instabilities.

Figure 4: (a) Time series of potential temperature for January 2005 to June 2007 from RaTS CTD data, with potential density $\sigma_{0}$ (in $\mathrm{kg} \mathrm{m}^{-3}$ ) overlaid; (b) As panel (a), but for salinity; (c) As panel (a), but for buoyancy frequency squared $N^{2}$. Values of $N^{2}$ were smoothed in depth using a 10-point filter. Note the strong summertime stratification in the upper $100 \mathrm{~m}$ and the deep winter mixed layers; (d) Percentage sea-ice cover and type from daily in-situ observations of Ryder Bay for the same period. The period with fast ice present is shorter in 2006 than in 2005. Antarctic Surface Water and Circumpolar Deep Water is marked in panels (a) and (b).

Figure 5: (a) Welch power spectra (8 overlapping Hamming windows) for depth averaged $u$ for the deployment period 25 January 2005 to 15 February 2006, divided into fast-ice-covered and fast-ice free periods; (b) As panel (a), but for v; (c) As panel (a) but for the deployment period 17 February 2006 to 16 December 2006; (d) As panel (b) but for the deployment period 17 February 2006 to 16 December 2006. In each plot, $95 \%$ confidence intervals on the spectral density estimate are indicated with error bars. Above $5 \mathrm{cpd}$, the spectra are band-averaged over 10 points.

Figure 6: (a) Depth structure of K1 tidal amplitudes for the first deployment period. 95\%

819 confidence intervals are indicated; (b) As panel (a) but for O1 amplitudes; (c) As panel (a) but for 820 M2 amplitudes; (d) K1 tidal ellipses for the deployment period 25 January 2005 to 15 February 821 2006, separated into fast-ice-free and fast ice covered portions; (e) As panel (d) but for O1; (f) As 822 panel (d), but for M2. The arrows show the direction of the rotation, and their position on the ellipse 823 shows the phase point. 
825 Figure 7: Rotary spectra of velocities ( $\log _{10}$ scale); (a) CCW spectra for fast-ice-free portion of the 826 second deployment period. (b) As panel (a), but CW rotation; (c) As panel (a), but for the fast-ice827 covered portion of the second deployment period; (d) As panel (b), but for the fast-ice-covered 828 portion of the second deployment period.

830 Figure 8: (a) Depth-averaged rotary coefficients $\left(\log _{10}(\mathrm{CW} / \mathrm{CCW})\right)$ evaluated from 30-day 831 overlapping spectra evaluated each day for the second deployment period. Blue values indicate a 832 dominance of counterclockwise energy. Times of fast ice cover are indicated, alongside K1, O1, 833 M2 and S2 tidal frequencies, and the inertial frequency $f$; (b) Rotary coefficient integrated between $834 \quad 0.9$ and $1.5 f$ for the same time period. Periods of fast ice cover are indicated in gray blocks. (c) 835 Seven-day low pass filtered wind speed (in $\mathrm{m} / \mathrm{s}$ ) for the second deployment period, from Rothera 836 meteorological station data (red line) and ECMWF ERA-Interim Reanalysis (blue line). The raw 837 data from which these filtered time series are derived are displayed in light red and light blue, and 838 periods of fast ice cover are indicated; (d) 0.9-1.5f band-pass filtered near-inertial current speeds for 839 the second deployment period, with fast-ice-covered periods marked; (e) 23-26 h band-pass filtered 840 diurnal tidal velocities for the second deployment period, with fast-ice-covered periods marked.

842 Figure 9: (a) Power spectrum (Welch estimate, 8 overlapping Hamming windows) of buoyancy 843 normalized shear variance $\left\langle V_{z} / N\right\rangle^{2}$ for fast-ice-covered and fast-ice-free period of the first 844 deployment; (b) As panel (a) but for the second deployment period. 95\% confidence intervals on 845 the spectral density estimate are indicated with error bars; 10 spectral points are averaged for 846 frequencies greater than $5 \mathrm{cpd}$.

848 Figure 10: (a) 2-hour low pass filtered ADCP $v$ velocities $\left(\mathrm{cm} \mathrm{s}^{-1}\right)$ for period around peak in $\varepsilon$ in 849 May 2006 (indicated with a red star); (b) Direction of shear vector between 0-100 m and 100-200 m 
850 for the same time period as panel (a). Counterclockwise rotating shear vectors of period close to the

851 inertial frequency $f$ are marked with black lines; (c) Accompanying hourly $u$ wind from the Rothera 852 meteorological station for the period of panel (d); (f) Accompanying hourly $v$ wind. The sense of 853 rotation of the wind velocity vector is indicated with labels.

855 Figure 11: (a) 2-hour low pass filtered ADCP $u$ velocities $\left(\mathrm{cm} \mathrm{s}^{-1}\right)$ for period around the minimum 856 in $\varepsilon$ in June 2005 (indicated with a blue star). Fast ice covered the site during this period, and water 857 column shear was dominated by the diurnal tide; (b) Direction of shear for the same time period. 858 Counterclockwise- and clockwise-rotating shear vectors of period close to the diurnal tide are 859 indicated with black lines; (c) Accompanying hourly $u$ wind from the Rothera meteorological 860 station for the period of panel (d); (f) Accompanying hourly $v$ wind. The sense of rotation of the 861 wind velocity vector is indicated with labels.

862 Tables

863

\begin{tabular}{|ccc|}
\hline & Rothera wind stress & ECMWF wind stress \\
\hline Fast-ice-free - deployment 1 & $\mathbf{- 0 . 3 5 ( 0 . 0 6 )}$ & $-0.07(0.72)$ \\
\hline Fast-ice-free - deployment 2 & $0.26(0.29)$ & $0.004(0.98)$ \\
\hline Fast-ice-covered - deployment 1 & $0.04(0.84)$ & $-0.07(0.71)$ \\
\hline Fast-ice-covered - deployment 2 & $-0.05(0.83)$ & $-0.06(0.79)$ \\
\hline
\end{tabular}

865 Table 1: Correlation coefficients (and $p$ values) for the relationship between 10-day low pass 866 filtered wind stress and depth-averaged rotary coefficient (from the ADCP) in the frequency range 867 1-1.7f. Statistically significant values (at 10\%) are highlighted in bold. Effective degrees of freedom 868 for calculation of the $p$ value were estimated from the first zero crossing of the autocorrelation 869 function. 


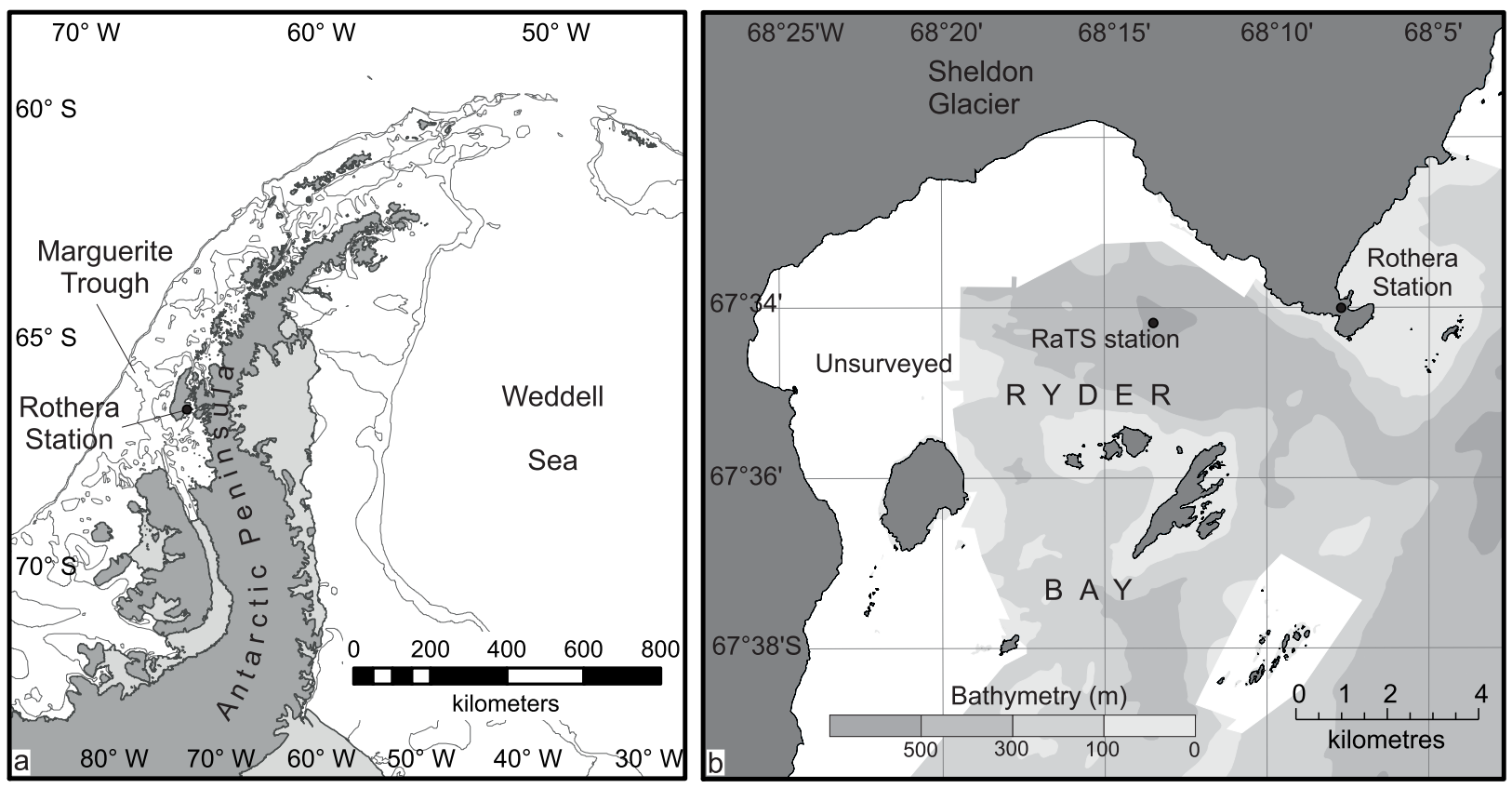



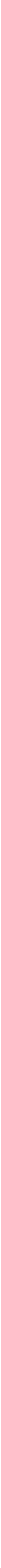
a
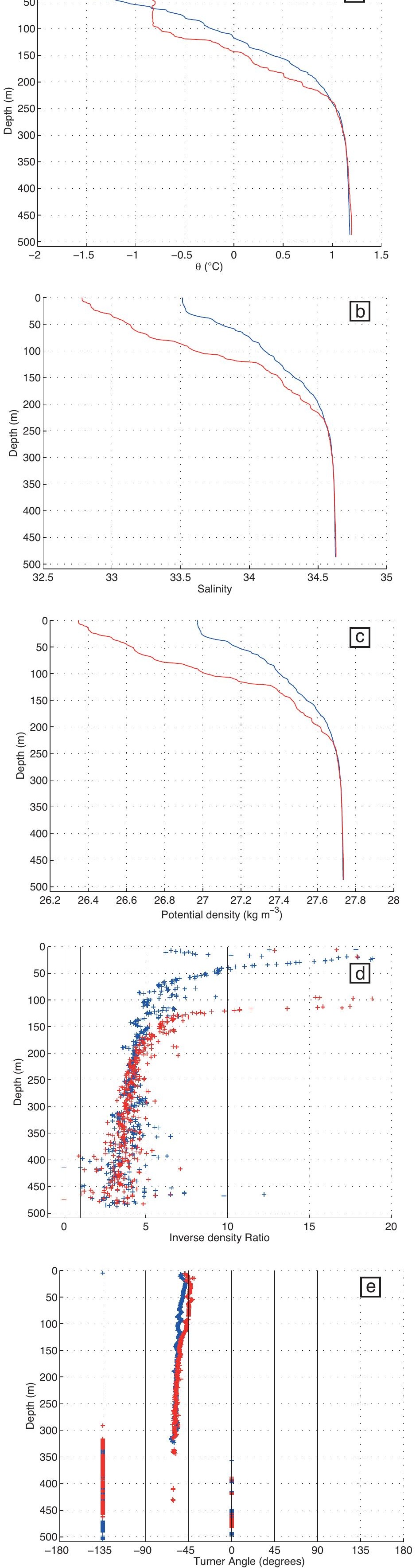

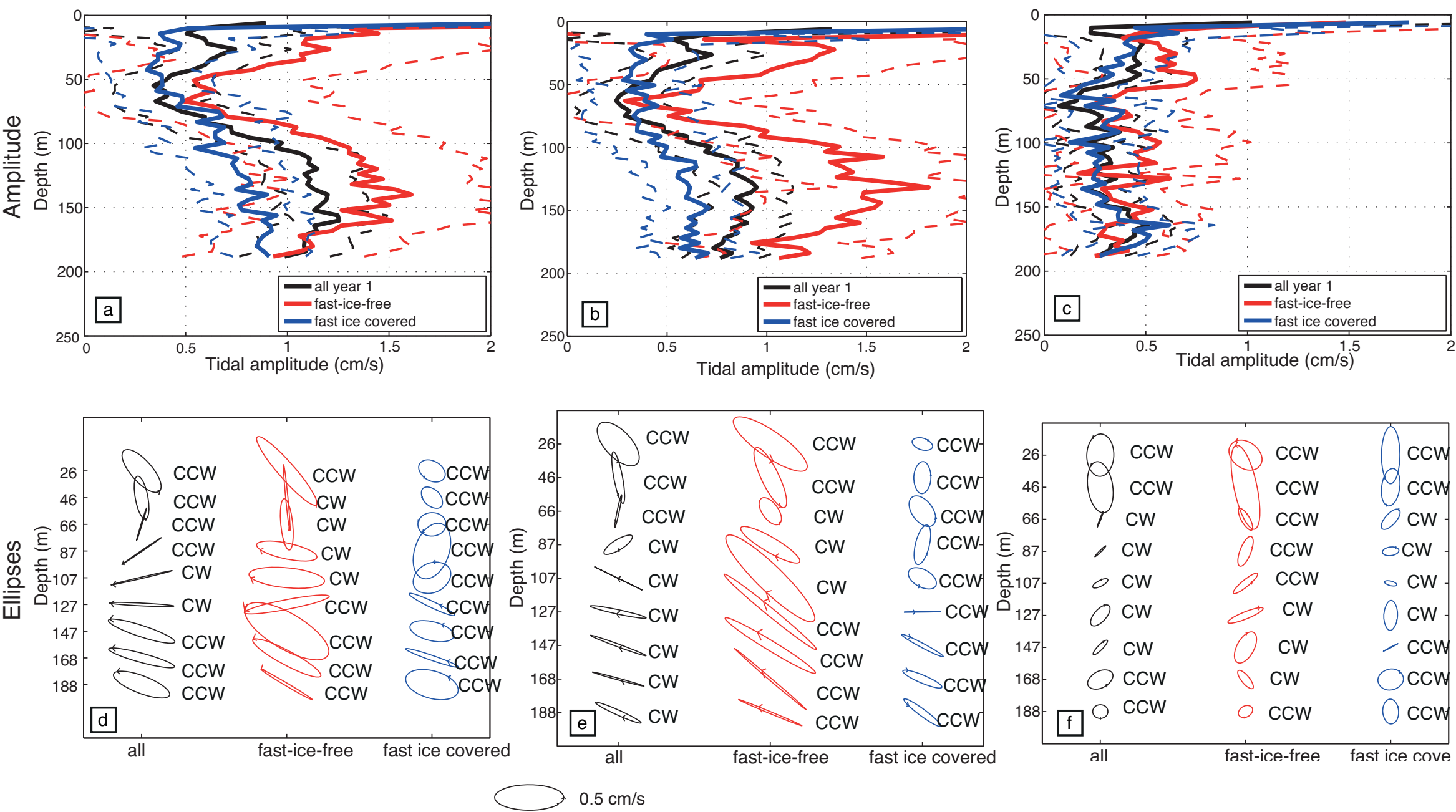

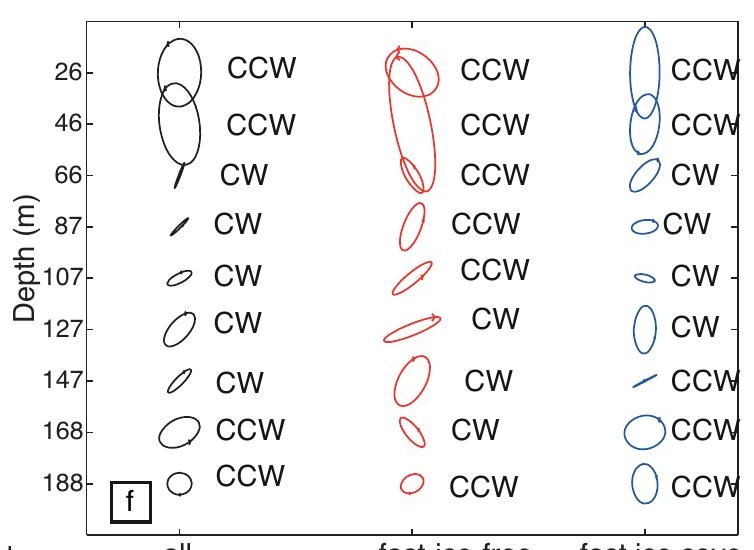

all

fast-ice-free

fast ice cove 
No fast ice

Fast ice covered
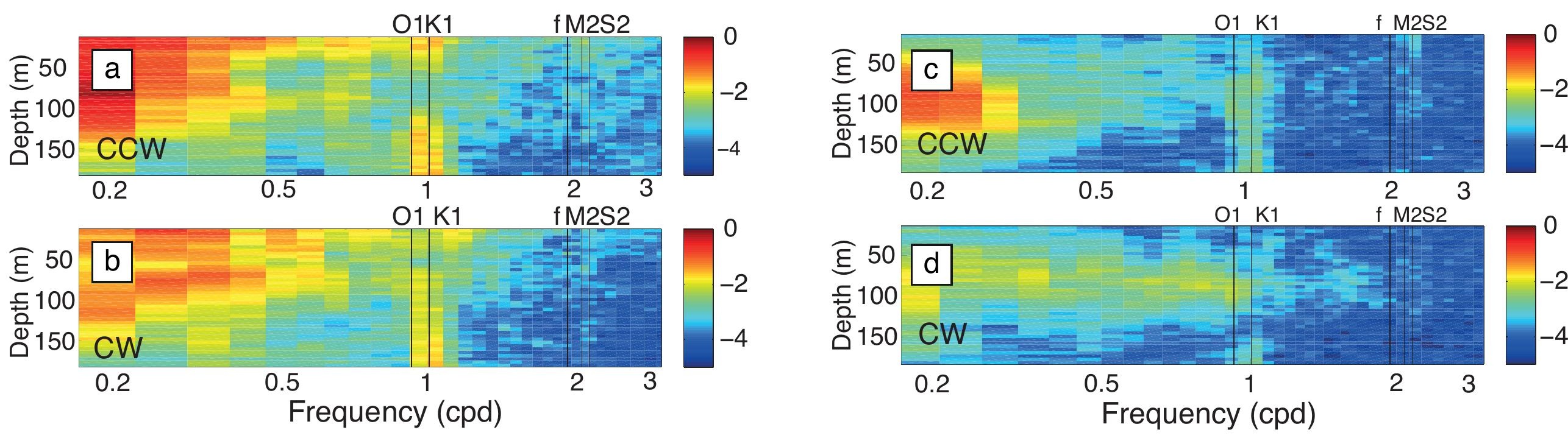

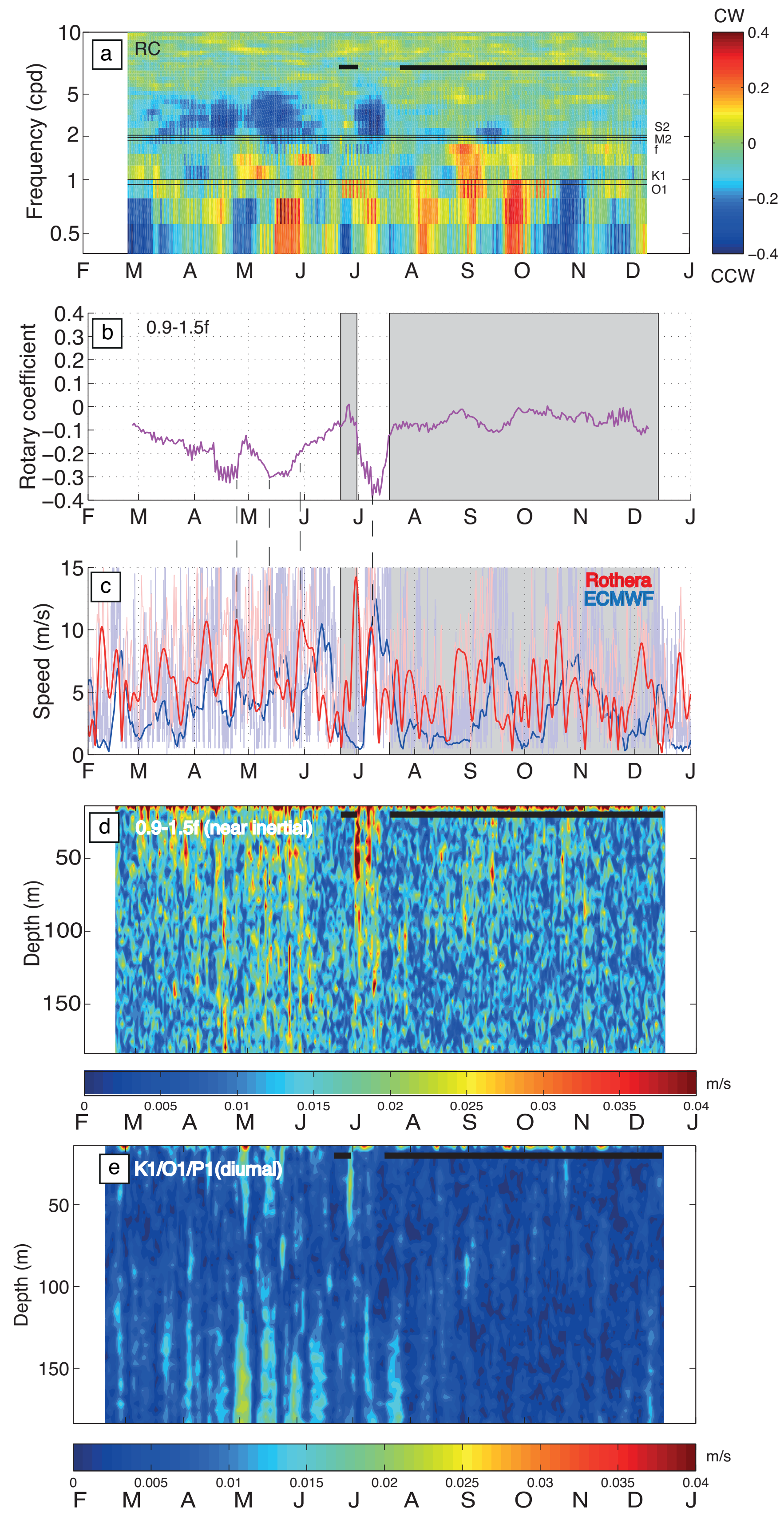

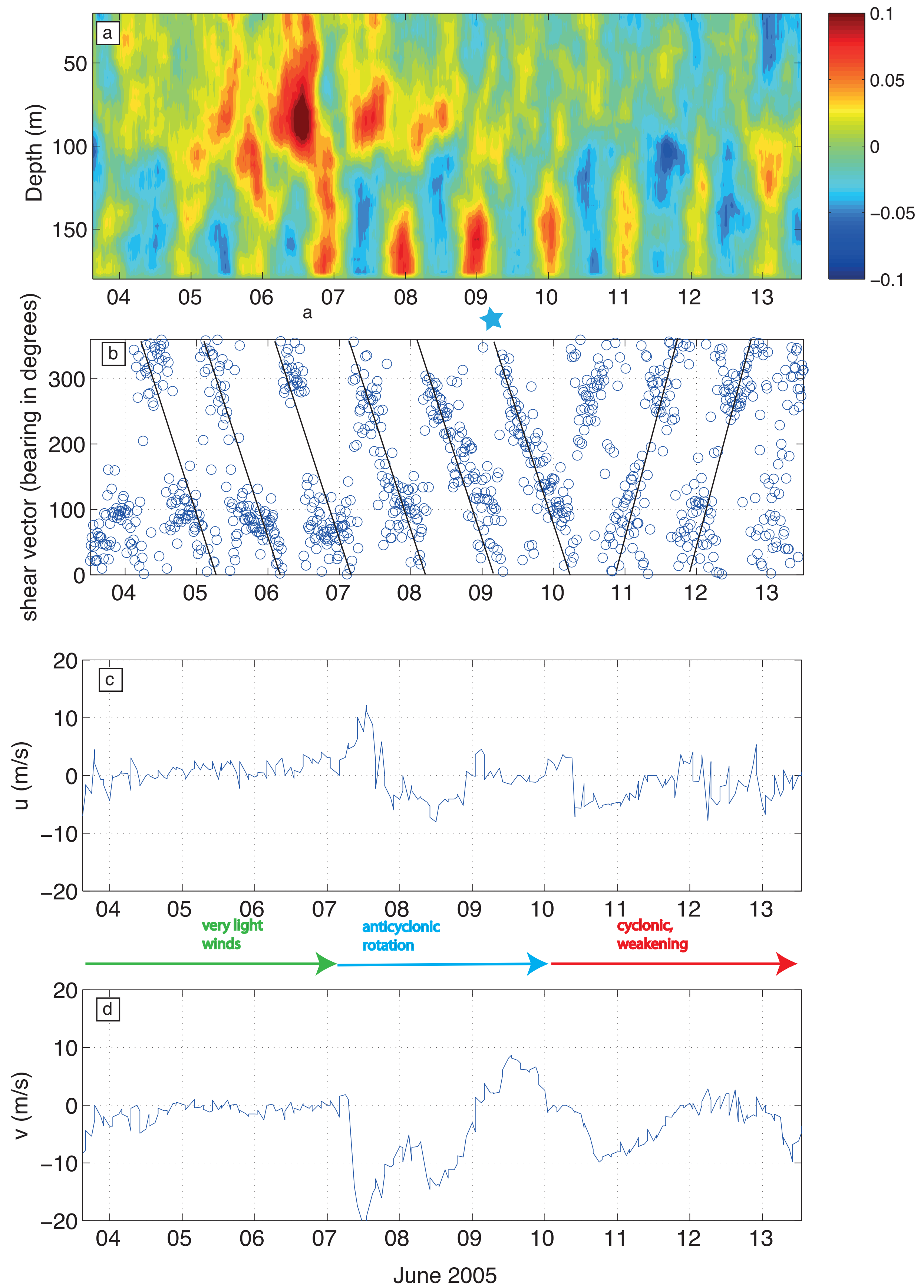